\title{
Teleconnections between Ocean-Atmosphere Coupled Phenomenon and Droughts in Tigray Region: Northern Ethiopia
}

\author{
Moges Molla \\ Ethiopian Environment and Forest Research Institute, Hawassa Center, Hawassa, Ethiopia \\ Email: ennu.moges@gmil.com
}

How to cite this paper: Molla, M. (2020). Teleconnections between Ocean-Atmosphere Coupled Phenomenon and Droughts in Tigray Region: Northern Ethiopia. American Journal of Climate Change, 9, 274-296. https://doi.org/10.4236/ajcc.2020.93018

Received: December 31, 2019

Accepted: September 7, 2020

Published: September 10, 2020

Copyright $\odot 2020$ by author(s) and Scientific Research Publishing Inc. This work is licensed under the Creative Commons Attribution International License (CC BY 4.0).

http://creativecommons.org/licenses/by/4.0/

\section{(c) (i) Open Access}

\begin{abstract}
Existing limited understanding on the teleconnections between ocean-atmosphere coupled phenomena and drought occurrences in Ethiopia has been undermining the decisions and interventions related to climate change adaptation and mitigation. The two drought indices Standardized Precipitation Index and Reconnaissance Drought Index were used for correlation and lag correlation with global indices El-Nino Southern Oscillation, Oceanic Nino, Indian Ocean Dipole and Pacific Decadal Oscillation. The indices were obtained from their respective database websites of the National Center for Environmental Prediction. Historical EL-Nino and La-Nina years and Ethiopian drought years were collected from literatures. Meteorological data on seasonal mean rainfall, maximum and minimum temperatures from 1916-2016 were collected from Tigray regional meteorology agency. In addition, the Cru/ Model data were collected from KNMI climate explorer. The analysis results the strong correlations of global indices Nino3.4, IOD and PDO with local indices for April to June rainy season while SOI and IOD indices for July-Sep. The positive correlation of indices weakened and/or dislocated the rain-producing components for main rainy season, while those systems enhanced in low rain season. This shows global indices alter rain fall distribution \& conveys Meteorological and Agricultural drought. The study revealed that, in addition to El Nino impacts, other events such as PDO, SOI and IOD are important factors for triggering meteorological and agricultural droughts in Tigray region of Ethiopia. This information has multiple implications, among others, improves seasonal forecast to make informed decisions.
\end{abstract}

\section{Keywords}

Teleconnections, ENSO, IOD, PDO, SPI, RDI 


\section{Introduction}

The changing climate due to anthropogenic emission and different drivers are causing climate variability and change. According to (NAPA, 2007) report of Ethiopia, the country is vulnerable to climate variability and change due to very high dependence on rain fed agriculture which is very sensitive to climate variability and change, under-development of water resources, low health service coverage, high population growth rate, low economic development level, low adaptive capacity, inadequate road infrastructure in drought prone areas, weak institutions and lack of awareness and hence climate change is expected to have adverse ecological, social and economic impacts in the country (NMA, 2007).

According to (Dawit, 2010), Ethiopia has different rainy seasons influenced by topographic variation and rain bearing systems. It is stated that the amount of rain over the mountain areas is higher than the lowlands, with the maximum rain received over the southwest and the minimum over the southeast of the country. The regional and global features that affect the kiremt rain include ITCZ, TEJ, South Atlantic Ocean and South West Indian ocean anticyclone, EALLJ or Somali Jet and ENSO. The Belg rain is affected by ITCZ, SWJ stream, Arabian High, the frequency of tropical cyclones over the Southwest Indian Ocean and ENSO. The knowledge on climate variability and the changing climate and also the fundamental climate pattern of the given region help policy makers to foresee how weather and climate may influence every aspect of the inhabitants and their socio-economic development. That is why at the world wide level efforts are made to investigate the climate variability and climate change in different seasons that prevail at local, regional and worldwide scales. Among this global explorations to improve the weather forecasting and climate predictions capabilities have remained on the top of the global agenda (Korecha et al., 2013).

Extreme events: These can influence agriculture quite heavily but projecting their impact is hard. Probably the best known such event is the El Niño Phenomenon that happens irregularly but dramatically affects the weather in many parts of the world. The term El Niño refers to the large-scale warming of surface waters of the Pacific Ocean every 3 - 6 years, which usually lasts for $9-12$ months, but may continue for up to 18 months and dramatically affect the weather worldwide. Predicting the occurrence of El Niño events (but not their impact on agriculture) has only been possible since the 1980 's when computing power became large enough to do so.

There are different coupled ocean atmosphere phenomenon globally that affects the weather and climate of different regions and countries. El Niño and La Niña, together called the ENSO, are periodic departures from expected SSTs in the equatorial Pacific Ocean. These warmer or cooler than normal ocean temperatures can affect weather patterns around the world by influencing high and low pressure systems, winds, and precipitation. ENSO may bring much needed moisture to a region while causing extremes of too much or too little water in 
others, (NOAA, http://www.esrl.noaa.gov/psd/enso/index.html). Statistical evidence shows that ENSO can account at most for about $50 \%$ of the inter annual rainfall variance in eastern and southern Africa and many of the more extreme anomalies, such as severe droughts, flooding, and hurricanes, have strong teleconnections to ENSO events, (http://drought.unl.edu/). Although the strongest signal of ENSO impacts is in the areas closest to the equatorial Pacific, El Niño and La Niña are such powerful forces that they can shift seasonal temperature and precipitation patterns around the globe.

PDO is often described as a long-lived El Niño-like pattern of Pacific climate variability. As seen with the better-known ENSO, extremes in the PDO pattern are marked by widespread variations in the Pacific Basin and the North American climate. In parallel with the ENSO phenomenon, the extreme phases of the PDO have been classified as being either warm or cool, as defined by ocean temperature anomalies in the northeast and tropical Pacific Ocean. When SSTs are anomalously cool in the interior North Pacific and warm along the Pacific Coast, and when sea level pressures are below average over the North Pacific, the PDO has a positive value. When the climate anomaly patterns are reversed, with warm SST anomalies in the interior and cool SST anomalies along the North American coast, or above average sea level pressures over the North Pacific, the PDO has a negative value (NOAA, 2016). Causes of the PDO are not currently known. Likewise, the potential oscillations are not known. The mechanisms giving rise to PDO will determine whether skillful decade's long PDO climate predictions are possible. Even in the absence of a theoretical understanding, PDO climate information improves season to season and year to year climate forecasts because of its strong tendency for multi seasonal and multiyear persistence (Mantua, 2000).

The Indian Ocean Dipole is a coupled ocean-atmosphere phenomenon in the Indian Ocean. It is normally characterized by anomalous cooling of SST in the south eastern equatorial Indian Ocean and anomalous warming of SST in the western equatorial Indian Ocean (JAMSTEC, 2008). The IOD involves a periodic oscillation of sea-surface temperatures, between positive, neutral and negative phases. A positive phase sees greater-than-average sea-surface temperatures and greater precipitation in the western Indian Ocean region, with a corresponding cooling of waters in the eastern Indian Ocean which tends to cause droughts in adjacent land areas of Indonesia and Australia. The negative phase of the IOD brings about the opposite conditions, with warmer water and greater precipitation in the eastern Indian Ocean, and cooler and drier conditions in the west, (Commonwealth of Australia, 2016). Like ENSO, the change in temperature gradients across the Indian Ocean results in changes in the preferred regions of rising and descending moisture and air.

Different studies reviewed by (Gisila, et al., 2015) found the association between strong ENSO events and regional climate anomalies over Ethiopia. These findings confirm that the fluctuations of atmospheric circulation, which are sometimes triggered by SST anomalies in the equatorial Pacific, have significant 
impacts on the position, magnitude, and intensity of the rain-bearing systems and caused meteorological, agricultural, and hydrological drought in Ethiopia. However, most of these studies focus on the association between EL Nino and rainfall anomalies. According to (Bekele, 1997) the classification and seasonal rainfall analysis of 224 rainfall stations in Ethiopia for the period 1969 up to 1987, the following relationships are concluded between Belg and Kiremt seasonal rainfall and eastern equatorial pacific sea surface temperature anomalies: a negative SSTA is strong associated with rainfall deficiency in Belg; a positive SSTA is mostly associated with normal and above normal rainfall amounts in Belg; the group one type of EL Nino is always associated with a severe and widespread meteorological drought in Ethiopia during Kiremt; the occurrence of group two type of EL Nino events seems to have relatively less negative effect on Kiremt rains, both in its amount and its spatial distribution; ENSO events may not be the only cause of meteorological drought in Ethiopia.

The association between the above coupled ocean atmosphere phenomenon and droughts in Ethiopia have not been well examined. This project is initiated to investigate the relationship between the changes in these global phenomenon and droughts in Ethiopia to point out the implications in early warning system. Drought preparedness planning has become a widely accepted tool for governments at all levels to apply to reduce the risks to future events. Drought plans should contain three basic components: monitoring and early warning, risk assessment, and mitigation and response. Because of drought's slow onset characteristics, monitoring and early warning systems provide the foundation for an effective drought mitigation plan. A plan must rely on accurate and timely assessments to trigger mitigation and emergency response programs.

Drought is a common condition of any climate of temporal recurring natural tragedy due to the luck of precipitation which brings economic, social political and resources fatalities. According to (Wilhite et al., 2000) drought is a normal, recurring feature of climate; it occurs in virtually all climatic regimes. It occurs above normal as well as below normal rainfall of areas. It is a temporary aberration, in contrast to aridity, which is a permanent feature of the climate and is restricted to low rainfall areas. Drought is the consequence of a natural reduction in the amount of precipitation received over an extended period of time, usually a season or more in length, although other climatic factors (such as high temperatures, high winds, and low relative humidity) are often associated with it in many regions of the world and can significantly aggravate the severity of the event.

Drought is also defined as a prolonged abnormally dry period when there is not enough water for users' normal needs, resulting in extensive damage to crops and a loss of yields. These definitions are conceptual explanations that provide the basis for the operational meaning. The operational definition of drought focuses on identifying the beginning, end, spatial extent, and severity of the drought in a given region and is based on scientific reasoning. The analysis is conducted by using hydro meteorological information and is beneficial in developing drought 
policies, early warning monitoring systems, mitigation strategies, and preparedness plans. Generally, the most prominent types of droughts are meteorological, agricultural, and hydrological droughts (Wilhite et al., 2000). Because of climate change and variability, drought has become a recurrent phenomenon in several countries across the globe. It is manifested in erratic and uncertain rainfall distribution in rainfall dependent farming areas, especially in arid and semi-arid ecosystems (Tsegaye, 2009).

Drought is conceived here as a temporary lack of water, which is necessary but not exclusively, caused by abnormal climate and which is damaging to an activity, group, or the environment. Although its impact does not come through sudden events such as flood and storms, drought is the world's costliest natural disaster, causing on an average $\$ 6$ - $\$ 8$ billion of global damages annually and collectively affecting more people than any other form of natural disaster (Wilhite et al., 2000; Obasi, 1994). Extreme weather events in Ethiopia significantly affect the agro-socio-economic environment. Droughts in northern, southern and eastern Ethiopia caused great human suffering and loss of life, (Seleshi \& Camberlin, 2006). Drought, rain fall delay, fire damage and heavy and unexpected rain fall are climate related hazards that mainly faced and also total crop loss, reduced yield, reduced seeding quality, delayed maturity and increased crop pest/disease are the major climate impacts, (Molla, 2016a).

Climate change is the sever problem that the whole world is facing today which is manifested by changing the intensity, duration or time of climate variables. Incidences of extreme weather events and large fluctuations in precipitation patterns, and shortening of the lengths of growing periods have been occurring with increasing frequency (IPCC, 2000). The extremes in climate variability may lead to droughts and floods. It is now widely accepted that climate change is already happening and further change is inevitable. Assessments that are carried out by the (IPCC, 2007) States the projected global surface warming lies within the range $0.6^{\circ} \mathrm{C}$ to $4.0^{\circ} \mathrm{C}$.

Drought is a normal, recurring feature of climate; it occurs in virtually all climatic regimes (Wilhite, 1992). Recent droughts have illustrated the vulnerability of people and environment due to extended periods of precipitation deficiency. (Smakhtin \& Hughes, 2004) stated that drought is a normal feature of any climate and it is a temporary, recurring natural disaster, which originates from the lack of precipitation and brings significant economic losses. It is not possible to avoid droughts. But drought preparedness can be developed and drought impacts can be managed. The success of both depends, amongst the others, on how well the droughts are defined and drought characteristics quantified.

Drought varies with regard to the time of occurrence, duration, intensity, and extent of the area affected from year to year. It is broadly classified into different categories. Meteorological drought indicates the deficiency of rainfall compared to normal rainfall in a given region. Hydrological drought indicates the scarcity of water in surface and underground resources. Agricultural drought occurs when the rainfall and soil moisture are inadequate to meet the water require- 
ments of crops.

Drought studies are important because of their influence on the society and the economy of any nation. It differs from other natural hazards by its slow accumulating process and its indefinite commencement and termination. Drought assessment involves analysis of spatial and temporal water related data. Several methods were developed to assess the drought quantitatively. Over the years, various indices have been developed to detect and monitor droughts. Hence characterization of different droughts using different indices is important to devise and use alternative early warning mechanisms to manage drought impacts and to implement adaptation and mitigation options and technologies. Drought preparedness planning has become a widely accepted tool for governments at all levels to apply to reduce the risks to future events. Drought plans should contain three basic components: monitoring and early warning, risk assessment, and mitigation and response. Because of drought's slow onset characteristics, monitoring and early warning systems provide the foundation for an effective drought mitigation plan. A plan must rely on accurate and timely assessments to trigger mitigation and emergency response programs (McKee, Doesken, \& Kleist, 1993).

Atmospheric and oceanic Teleconnections govern the variability in our climate system on a broad range of time and spatial scales, in both the tropics and extra-tropics. On inter-annual time scales, the connection between El NiñoSouthern Oscillation and the Asian monsoon system influences rain amounts in regions particularly sensitive to floods/droughts. On inter-annual and decadal time scales, rainfall variability in the Sahel region of West Africa appears to be governed to a large extent by Teleconnections patterns related to the Pacific Ocean, the Indian Ocean, and the Atlantic Ocean. The seasonally stratified correlation between the indices of IOD and ENSO peaks at 0.53 in SeptemberNovember. This means that only one third of IOD events are associated with ENSO events.

The decadal behavior of the North Atlantic Oscillation, influencing climate in Europe, Asia, and northern Africa, is also likely to be connected to both tropical and extra-tropical sea surface temperatures in the Indo-Pacific and Atlantic regions. The first panel discussion focused on general issues related to teleconnections and mechanisms connecting tropical and extra tropical regions. One of the main questions raised during this discussion was whether teleconnections are useful for climate predictions. The panel agreed that teleconnections can be used as a predictive tool and to aid the understanding and improvement of predictive skill in seasonal forecasts (Cf. Philander, 2004).

At topical period, the tricky of climate variability and climate change, due to anthropogenic as well as natural processes, has come with daily wicked news (Molla, 2016b). It should also be noted that ENSO is not the only cause of floods and droughts in the sub region. There is a need for more regional research to understand other causes of climate anomalies in the region. ENSO can, however, account for more than $80 \%$ of the rainfall anomalies in some seasons and loca- 
tions. This signifies the importance of ENSO, SSTs, and other general circulation information for purposes of early warning in the sub region. The association between the above coupled ocean atmosphere phenomenon and droughts in Ethiopia have not been well examined. This project is initiated to investigate the relationship between the changes in these global phenomenon and droughts in northern Ethiopia to point out the implications in early warning system.

\section{Materials and Methods}

\subsection{Description of Study Area}

Tigray region (Figure 1) Station distribution map of the study area, situated between $12015^{\prime}$ and $14^{\circ} 57^{\prime} \mathrm{N}$ latitude $36^{\circ} 27^{\prime} \mathrm{E}$ and $39^{\circ} 59^{\prime} \mathrm{E}$ longitude, is in the northern part of the nine regions of Ethiopia. The language mainly spoken in the region is Tigrigna. Mekelle is the capital city of the region. It covers an approximate surface area of $54,572 \mathrm{~km}^{2}$. Altitude varies from about 500 . Tigray region (Figure 1) Station distribution map of the study area, situated between 12015 and $14^{\circ} 57^{\prime} \mathrm{N}$ latitude $36^{\circ} 27^{\prime} \mathrm{E}$ and $39^{\circ} 59^{\prime} \mathrm{E}$ longitude, is in the northern part of the nine regions of Ethiopia. The language mainly spoken in the region is Tigrigna. Mekelle is the capital city of the region. It covers an approximate surface area of $54,572 \mathrm{~km}^{2}$. Altitude varies from about 500 meters above sea level (masl) in the northeast to almost 4000 masl in the southeast. According to the agro-climatic classification of the area, about $53 \%$ of the land is below 1500 masl and is classified as lowland (kola), 39\% situated at 1500 - 2300 masl and known as medium altitude (weinadega) and 8\% is over 2300 masl and is classified as highland (dega) (Beyene, Gibbon, \& Haile, 2005). Alamata is one of the case study areas which is located at a points $12.4197 \mathrm{~N}, 39.5537 \mathrm{E}$ and $1560 \mathrm{~m}$.

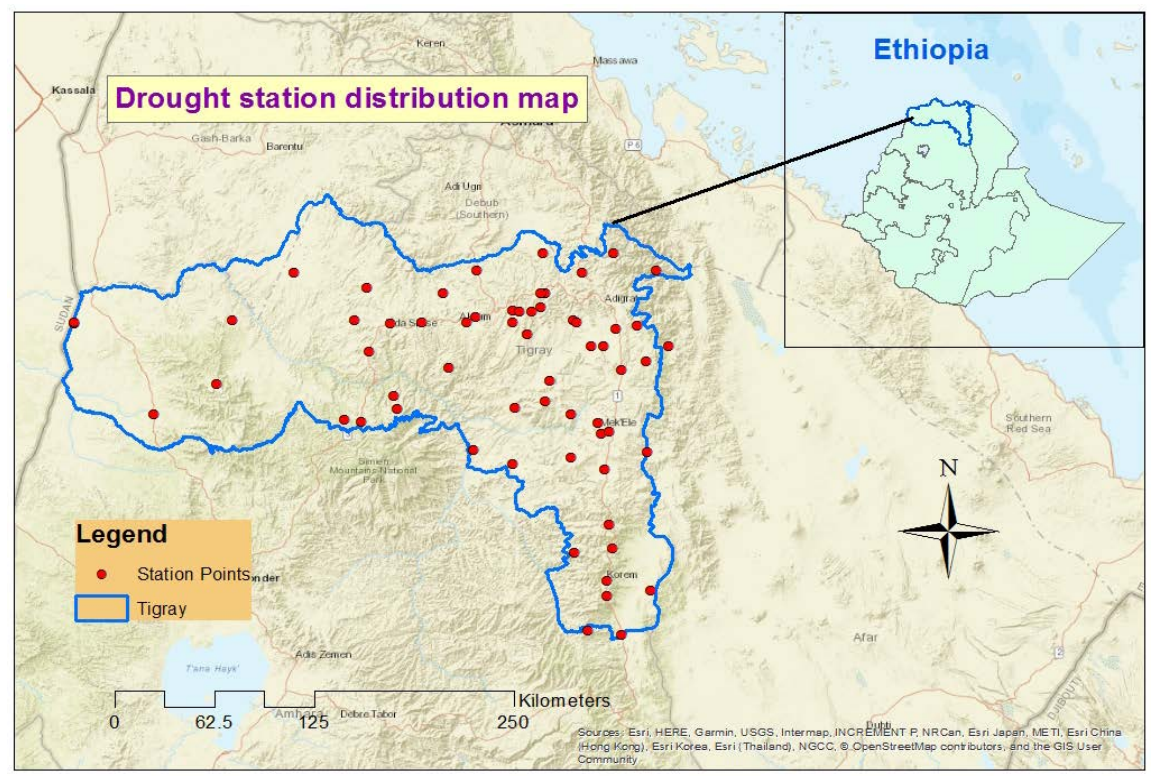

Figure 1. Station distribution map of the study area. 


\subsection{Sources of Data}

Data for this study was collected from different sources. El-Nino3.4, Southern Oscillation Index, Pacific Decadal Oscillation and Indian Ocean Dipole indices were downloaded from their respective database websites of NOOA and National Center for Environmental Prediction. Stations data on seasonal mean rainfall, max temperature, min temperature and Potential Evapo-transpiration for the years 1916-2016 years were obtained from NMA and Cru/Modeled data was obtained from KNMI climate explorer.

\subsection{Data Analysis}

To investigate teleconnections between ocean-atmosphere coupled phenomena and local drought occurrences, two drought indices that is Standardized Precipitation Index (Komuscu, 1999) and Reconnaissance Drought Index were used. Seasonal mean rainfall, max temperature, min temperature, Potential Evapo-transpiration of stations for the years 1916-2016 years were used as an input to calculate and characterize meteorological droughts and Agricultural drought using DrinkC software (Gibbs \& Maher, 1967). Then SPI and RDI were correlated with global climate indices (ENSO, SOI, PDO and IOD) for different seasons (July to Sept and April to June). Missing data (very few) are filled up using long term mean. The study also used the Cru/Modeled data from KNM climate explorer in addition to the observed data for SPI and RDI analysis.

Historical EL-Nino and La-Nina years and Ethiopian drought years were collected to investigate if El Nino events trigger droughts in Ethiopia or not. El Niño years are identified to be 1965, 1966, 1969, 1972, 1982, 1986, 1987, 1990, 1991, 1992, 1993, 1994, 1997, LaNiña years to be 1964, 1971, 1973 1974, 1975, 1988, 198 and 1999, and finally normal years were identified as: 1967, 1968, 1970, 1976, 1977, 1978, 1979, 1980, 1981, 1983, 1984, 1985, 1989, 1995 and 1996 based on (Hassan, 2009). The LaNiña and El Niño category include years with weak, moderate and strong events of the corresponding episode (Hassan, 2009).

A correlation analysis and regression analysis was conducted to investigate Teleconnections between ocean-atmosphere coupled changes and droughts in Ethiopia. In the linear regression analysis the drought indices were considered as dependent variable and the ENSO, SOI, PDO and IOD indices were considered as independent variables.

$$
y=b x+a+e
$$

where: $y$ is the dependent variable (drought indices),

$x$ is the independent variable (ENSO, SOI, PDO and IOD indices),

$b$ is the slope, $a$ is the y intercept when $x$ is zero and $e$ is the error if the regression equation.

The least square method was used to fit the data that minimizes the sum of the squared residuals. The slope $\mathrm{b}$ of the least square line is given by Equation (2) and the intercept of the least squares line is given by Equation (3). 


$$
b=\frac{S S_{x y}}{S S_{x x}}
$$

where: $S S_{x y}$ is the sum of the cross-products and

$S S_{x x}$ is the sum of the squares for the variable $x$.

$$
a=\bar{y}-b \bar{x}
$$

Based on the findings of relations between droughts and ocean-atmosphere coupled changes (the strength of relationships and the time lag), were identified.

\section{Reconnaissance Drought Index (RDI)}

$\mathrm{RDI}$ is a new index that involves precipitation and temperature, which are key factors to characterize the climate of a region. The indices calculation uses precipitation and evapo-transpiration which incorporates temperature variable in its computation. RDI has 3 forms: the intial value $\left(\alpha_{k}\right)$, the normalized form $\mathrm{RDI}_{n}$, and the standardized form $\mathrm{RDI}_{s t}$ However, the standardized form would be used for the characterization of droughts. The initial value $\left(\alpha_{k}\right)$ is calculated for the $i$-th year in a time basis of $\mathrm{k}$ (months) as follows: (Tigkas, 2015)

$$
\alpha_{k}^{(i)}=\frac{\sum_{j=1}^{k} P_{i j}}{\sum_{j=1}^{k} \operatorname{PET}_{i j}}, i=1(1) N \text { and } j=1(1) k
$$

where $P_{i j}$ and $\mathrm{PET}_{i j}$ are the precipitation and potential evapotranspiration of the $j$-th month of the $i$-th year and $N$ is the total number of years of the available data. The normalized form $\mathrm{RDI}_{n}$ is computed using the following Equation (5):

$$
\mathrm{RDI}_{n}^{(i)}=\frac{a_{k}^{(i)}}{\overline{a_{k}^{(i)}}}-1
$$

in which $a_{k}^{(i)}$ is the arithmetic mean of the $a_{k}^{(i)}$

By assuming log normal distribution, the standardized RDI values were calculated as follows:

$$
\mathrm{RDI}_{s t}^{(i)}=\frac{y^{(i)}-\bar{y}}{\hat{\sigma}}
$$

in which $y_{i}$ is the $\ln a_{k}^{(i)}, \bar{y}$ is its arithmetic mean and $\hat{\sigma}_{y}$ is its standard deviation.

For real world applications RDI is calculated as a general indicator of meteorological drought and it was calculated for 3, and 12 months scale. The drought classification in SDI is similar to that of SPI (Table 1). Intensity of the droughts was characterized using the value of RDI in Table 1 duration of droughts was analyzed based on the period in which the RDI values are below zero (Tigkas, 2015).

\section{SPI (standardized precipitation index)}

SPI (standardized precipitation index) (Tigkas, 2015) has the advantages of being easily calculated, having modest data requirements, and being independent 
Table 1. Classification of droughts based on standardized SDI values.

\begin{tabular}{cc}
\hline RDI $_{s t}$ & Category \\
\hline 2 or more & Extremely wet \\
1.5 to 1.99 & Severely wet \\
1 to 1.49 & Moderately wet \\
0 to 0.99 & Normal condition-wet \\
0 to -0.99 & Normal condition-dry \\
-1 to -1.49 & Moderate drought \\
-1.5 to -1.99 & Severe drought \\
-2 or less & Extreme drought \\
\hline
\end{tabular}

Source: Tigkas, 2015.

of the magnitude of mean rainfall and hence comparable over a range of climatic zones. It does, however, assume the data are normally distributed, and this can introduce complications for shorter time periods. The study showed the relationship between drought duration and drought time scale using the SPI Equation (7).

$$
\mathrm{SPI}=\frac{X_{i k}-X_{i}}{\mathfrak{d}_{i}}
$$

where,

$\mathrm{o}_{i}=$ standardized deviation for the $i_{\mathrm{th}}$ station.

$X_{i k}=$ precipitation for the $i_{\mathrm{th}}$ station and $k_{\mathrm{th}}$ observation.

$X_{i}=$ mean precipitation for the $i_{\mathrm{th}}$ station.

\section{Deciles}

Deciles approach suggested by (Gibbs \& Maher, 1967) were widely used method was applied. Monthly precipitation totals from a long term records are first ranked from highest to lowest to construct a commutative frequency distribution. The distribution is then split in to ten parts (tenths of distribution or deciles). The first deciles is the precipitation value not exceeded by the lowest $10 \%$ of all precipitation values in a record is between the lowest $10 \%$ and $20 \%$ etc. According to the author classification (Table 3) deciles are grouped in five classes, two deciles per classes.

\section{Results and Discussion}

\subsection{Teleconnections of SPI and RDI with Global Indices for Alamata}

Figure $2 \&$ Figure 3 indicate that the positive SPI values indicates greater than mean precipitation and negative values indicate less than mean precipitation. A drought occasion starts when SPI value reaches -1.0 and ends when SPI greater or equal to zero becomes non-drought positive again. As the analysis result of Alamata station indicates, the SPI values for years 1988 and 1999 was ranged extremely wet non drought years for July to Sep rain seasons but for years 1984, 


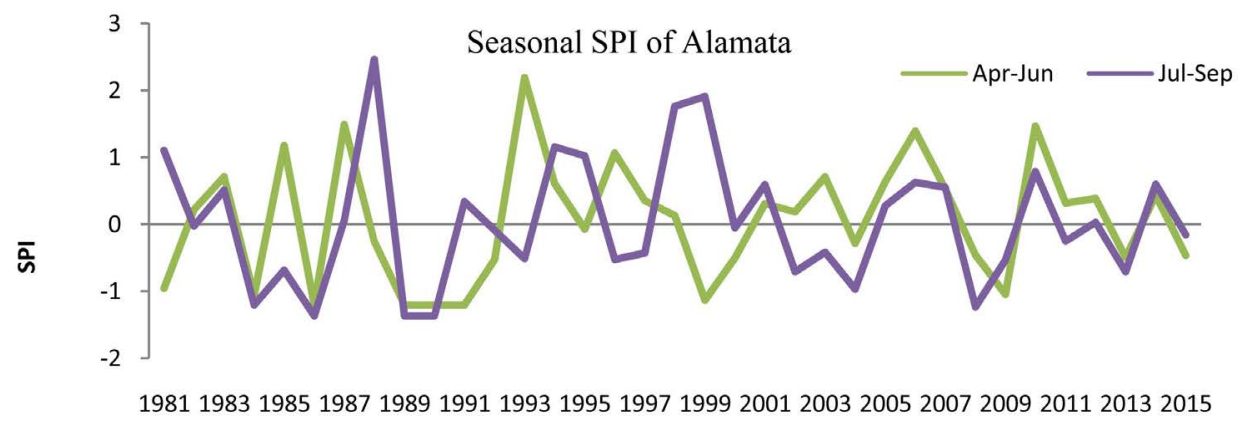

Figure 2. Teleconnections of annual SPI with global indices for Alamata.

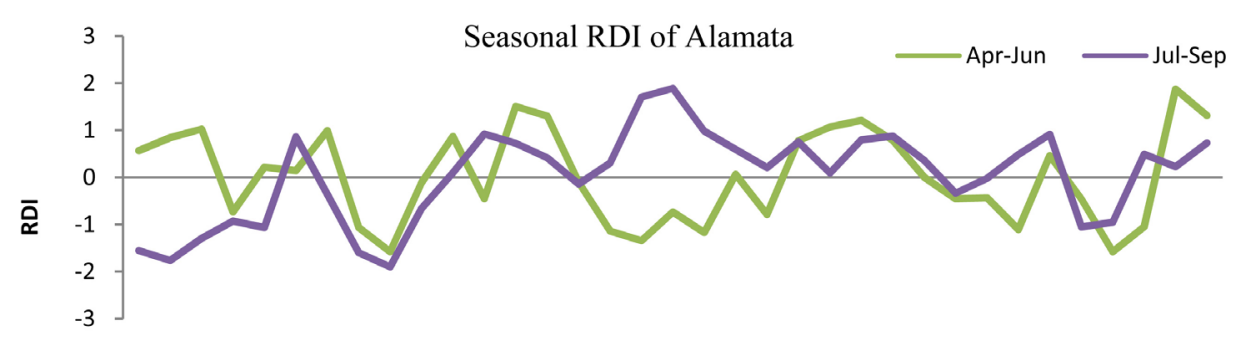

Figure 3. Teleconnections of annual RDI with global indices for Alamata.

1986 and 2008 SPI value was below -1 which indicates moderate drought years. While from 1993-200/3 moderate RDI was observed for April to Jun the reverse was true for July to Sept rain season and also it indicates that sever RD on $1981 / 82,1989,2012 / 2013$ at both rain seasons at the given station.

Figure 4 \& Figure 5 shows that the global indices Nino3.4 and PDO has positive relation or concedes with local drought SPI and RDI but the IOD more relies with SPI and RDI for years 1982, 1983, 1985, 1988, 1991, 1992, 1995, 1999, $2001,2002,2003,2005,2007,2012,2014$. This shows that SOI is not the only factor for drought of the area but also PDO and IOD do. The annually stratified correlation between the indices of IOD and ENSO peaks concede and the events are associated in some years. But a large number of IOD events are not associated with ENSO events. That is the independent nature of IOD is examined using correlation and lag correlation.

Similarly, Figure 6 \& Figure 7 indicated that the seasonal relations ship of reconiacence drought indices with global indices. In Figure 6, PDO and ENSO are positively correlated with April to June rain season for most of years and negatively correlated with for some moderate drought years like 1992, 2002, 2008/ 910 and 2013/14 while in Figure 7, PDO is negatively correlated with severe drought years like 2012 and 2014. Most of the above drought years are associated with Elino years, like 1982, 1986, 2008/9, 2002/3 2015/16 (Smakhtin \& Hughes, 2004) which indicates the local droughts are more linked with the global indices that shows teleconnections $\mathrm{b} / \mathrm{n}$ local and global indicates. These all shows the indications for the global indices (Nino3.4, IDO and PDO) and the major factors that alters climate of the area. 


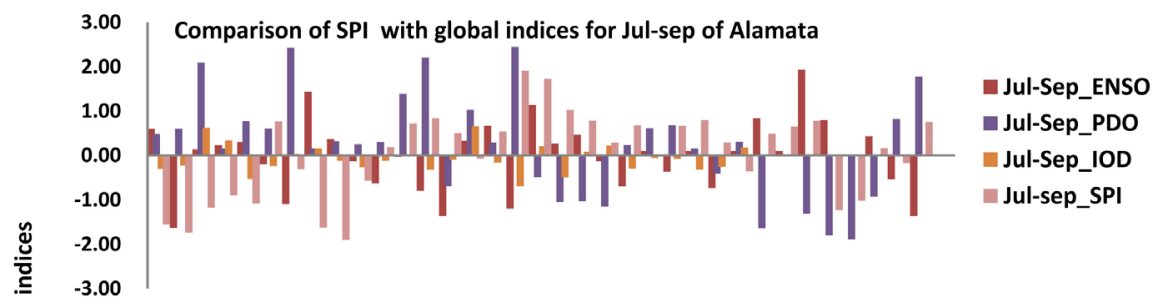

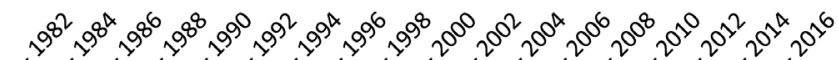

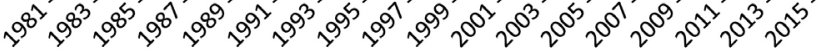

Figure 4. Comparison of seasonal SPI with global indices of Alamata.
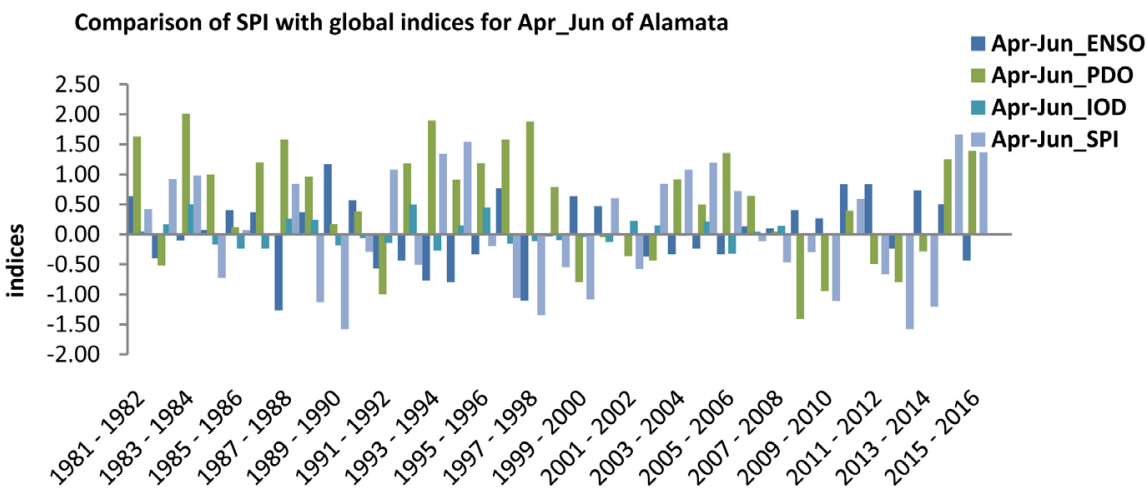

Figure 5. Comparison of seasonal SPI with global indices of Alamata.
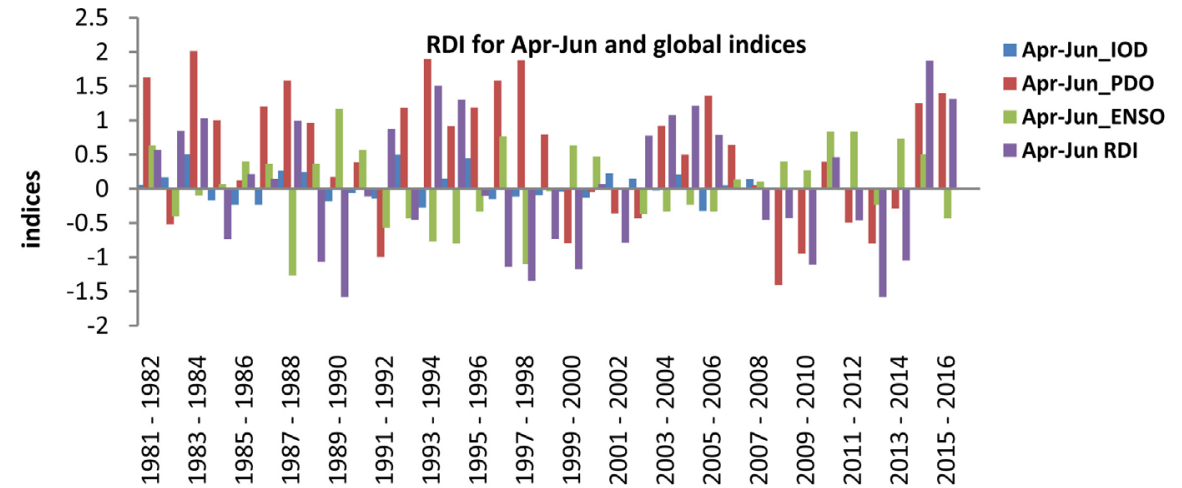

Figure 6. Comparison of seasonal SPI with global indices of Alamata.
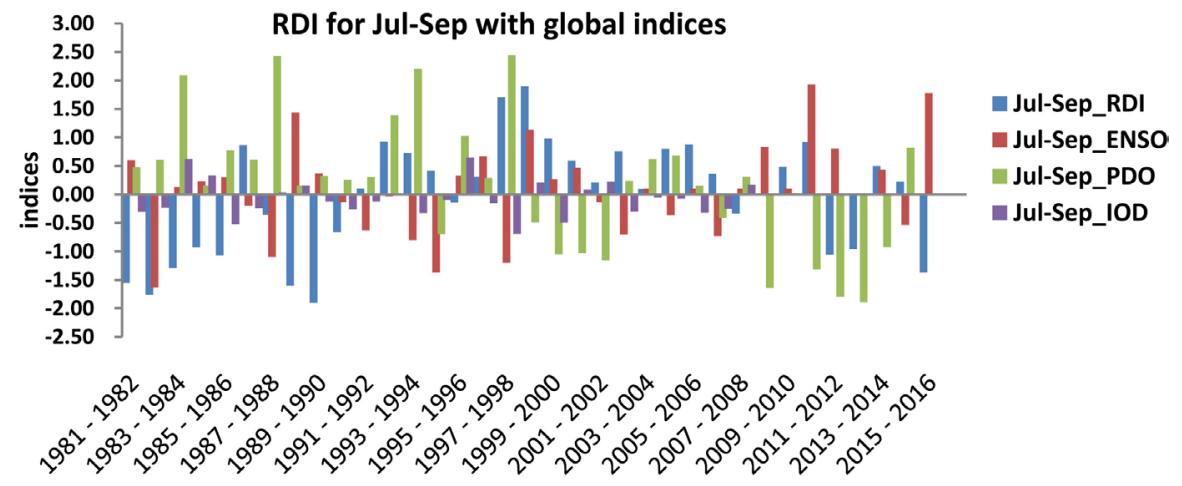

Figure 7. Comparison of seasonal SPI with global indices of Alamata. 


\subsubsection{Correlation and Lag Correlation of the Local and Global Indices} (Alamata)

The correlation result of (Figure 8) below indicates that global indices Nino3.4 and PDO are strongly correlated with local SPI of April to June rain. Similarly SOI and IOD work the same for July-Sep rainfall. The lag correlation also shows that PDO and IOD are strongly correlated with Lag 3 and lag 6 months of April to June and July to Sept rain season respectively except for IOD (Figure 8) below.

The correlation result of (Figure 9) below indicates that Nino3.4, PDO and IOD are positively correlated with local RDI for both rainy seasons. Global indices SOI and IOD are negatively correlated with July to Sep rain season. The lag correlation shows that PDO and Nino3.4 positively correlated with Lag 3 and lag 6 months for both rainy seasons. In fact there are also numerous mountains and valleys which could influence the weather of Ethiopia that made it more complicated. The analysis indicates that global ocean atmospheric phenomena PDO and IOD) are also another important factors which has not got credit as much as Elnino3.4.

Analysis of the precipitation conditions indicated (Table 1 and Table 2) above is based on the classification two droughts indices SPI and RDI respectively indicated that below normal rain/under SPI drought for Kiremt (July-Sept) rains in 1972, 1982, 1987, 1997, 2003/4, 2015/2016 has been associated with ENSO events.

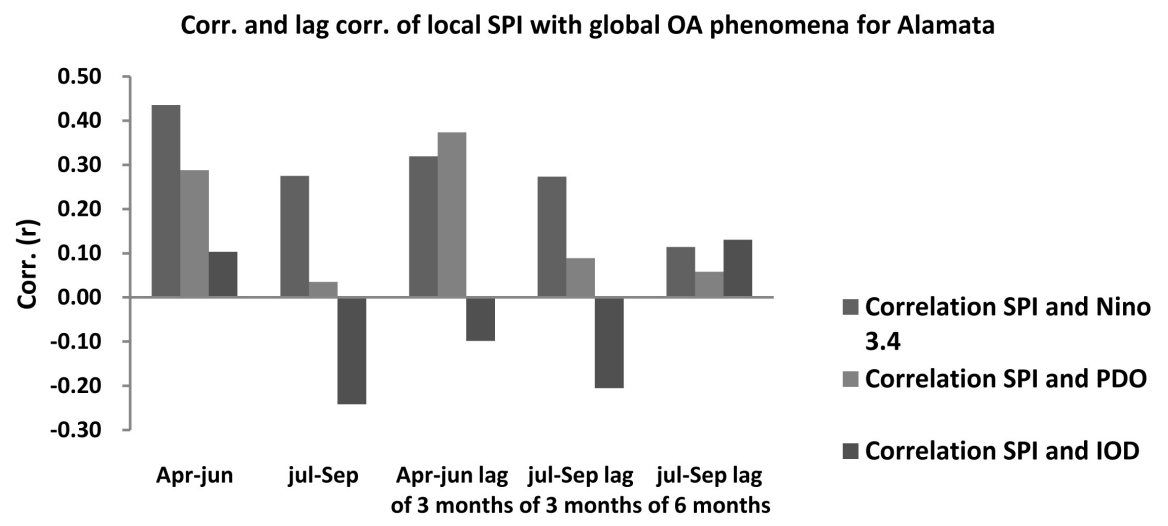

Figure 8. Correlation and lag correlation result of GOAP with local SPI of Alamata.

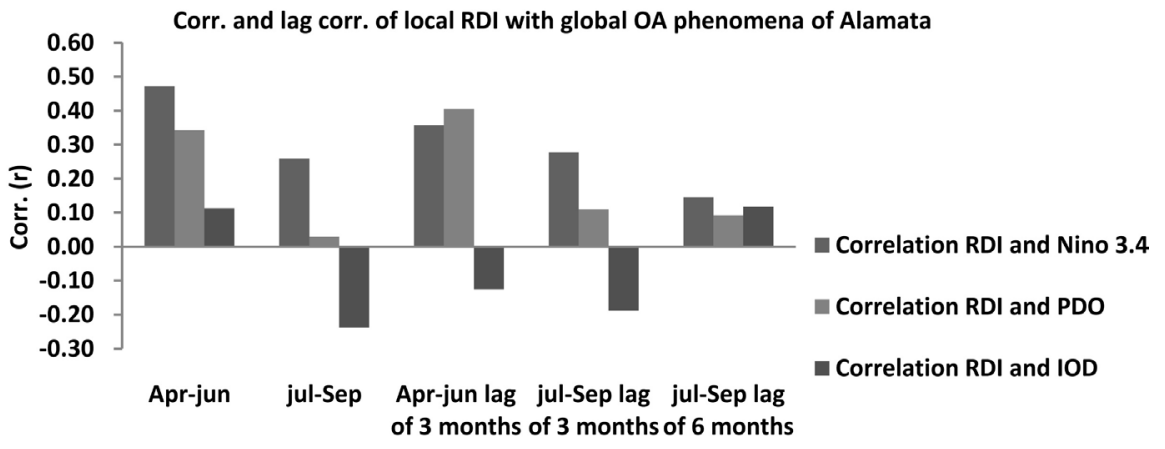

Figure 9. Correlation and lag correlation result of GOAP with local RDI of Alamata. 
Table 2. Classification of droughts based on standardized SPI values.

\begin{tabular}{cc}
\hline Drought class & SPI value \\
\hline Non-drought & SPI $\geq 0$ \\
Mild drought & $-1<$ SPI $<0$ \\
Moderate drought & $-1.5<$ SPI $\leq-1$ \\
Severe/extreme drought & SPI $\leq-1.5$ \\
\hline
\end{tabular}

Consequently, deficient rains in (July-Sept) and abundant rains in (Apr to Jun) seasons appear to be influenced by the ENSO events. The (July-Sept) and (Apr to Jun) seasonal mean of Southern Oscillation Index (SOI) is positively and negatively correlated to (July to Sep) and (Apr to Jun) rains respectively. Similarly, SST of central and eastern Pacific Nino3.4 is negatively correlated to (July to Sep) rains and positively correlated to (Apr to Jun) rains. This means that during El-Nino years, the atmospheric circulations particularly in the tropics would be disturbed. As a consequence, the rain-producing components for Kiremt would be weakened and/or dislocated, while those systems in Belg would be enhanced. Not only the Nino3.4 but also SOI, PDO and IOD have also both positive and negative influence depending on the weather stations.

\subsubsection{Annual Deciles of Rain Fall Distribution for Alamata}

The first decile's precipitation value not exceeded by the lowest $10 \%$ of all precipitation values in a record is between the lowest 10 and $20 \%$ etc. According to the deciles classification (Table 3), the years 1983, 1984, 1988, 1989, 2011, 2012 and 2016 are classified as much below normal distribution of precipitation as indicated in Figure 10.

\subsection{Teleconnections of SPI and RDI with Global Indices for Mekele}

As indicated in Figure 11, the annual SPI for was falls b/n some years like 1984, 1986, 1989, 1990 and 2008 of both rainy seasons of the station range $b / n-1.5<$ SPI $<-1$ which relies on moderate drought years, in opposite, years like 1985, 1988, 2006, and 2010 are ranged as non-drought years. Similarly, Figure 12 shows interconnections of RDI of the two rain seasons (July to Sept and Apr to Jun). The annual correlation between the indices of IOD peaks concedes with SPI and RDI in 1985, 1988, 1995 and 2001 and Nino3.4 and PDO peaks concede with 1982, 1983, 2000 and 2006 rain and the events are associated with ENSO events as compared to seasonal rainfall and the global indices.

The correlation results indicated in Figure 13, Nino3.4, PDO and IOD are positively correlated with local standardized precipitation index (SPI) but Southern Oscillation index (SOI) correlate negatively with local SPI of April to June rain season and similarly SOI and IOD also positively correlated with July to Sept rain season and negatively correlated with Nino3.4. 


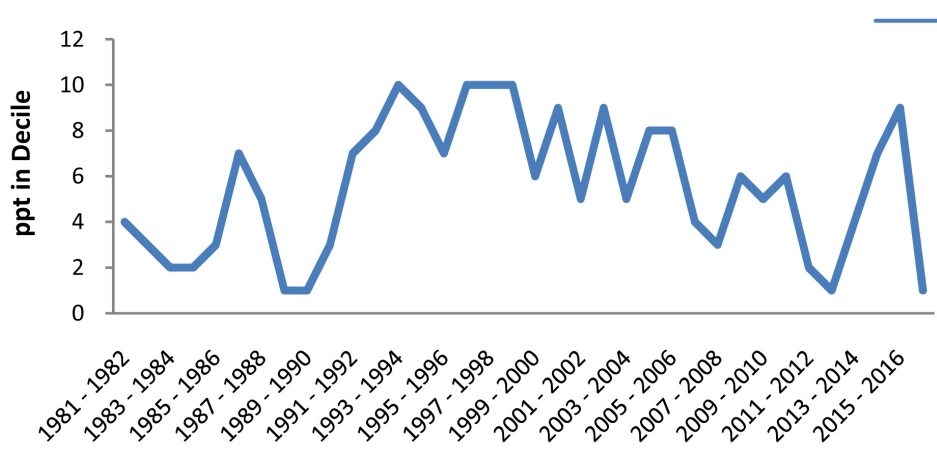

Figure 10. Annual deciles of Alamata.

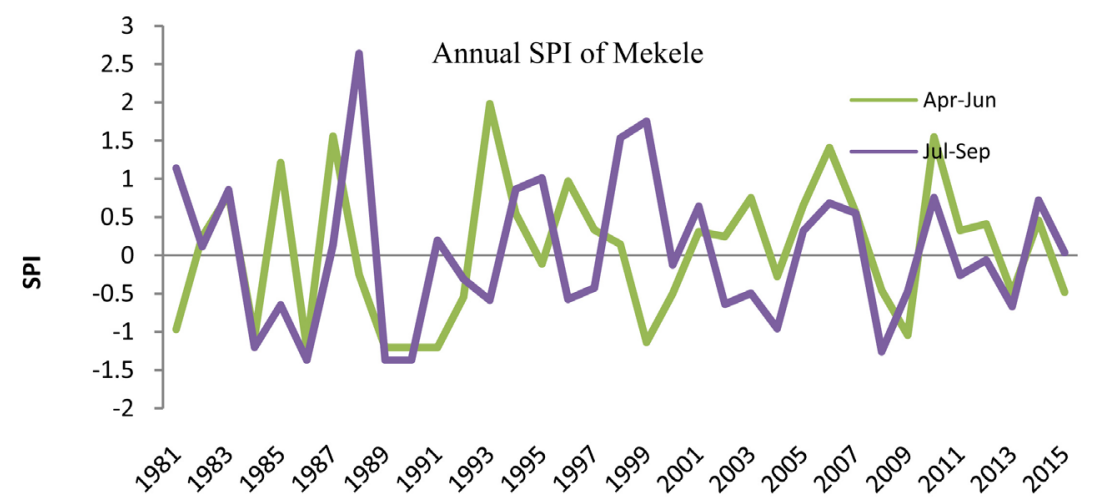

Figure 11. Teleconnections of annual SPI with global indices of Mekelle.

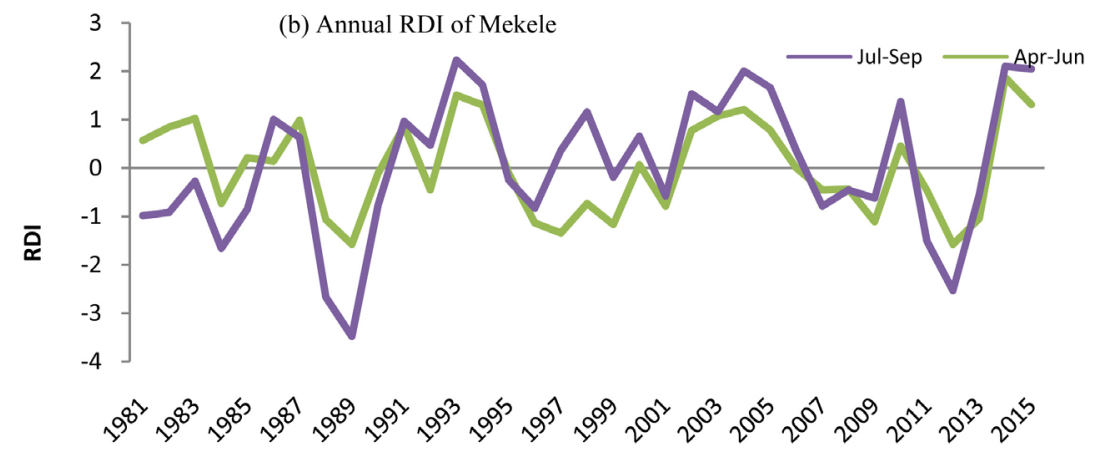

Figure 12. Teleconnections of annual RDI with global indices of Mekelle.

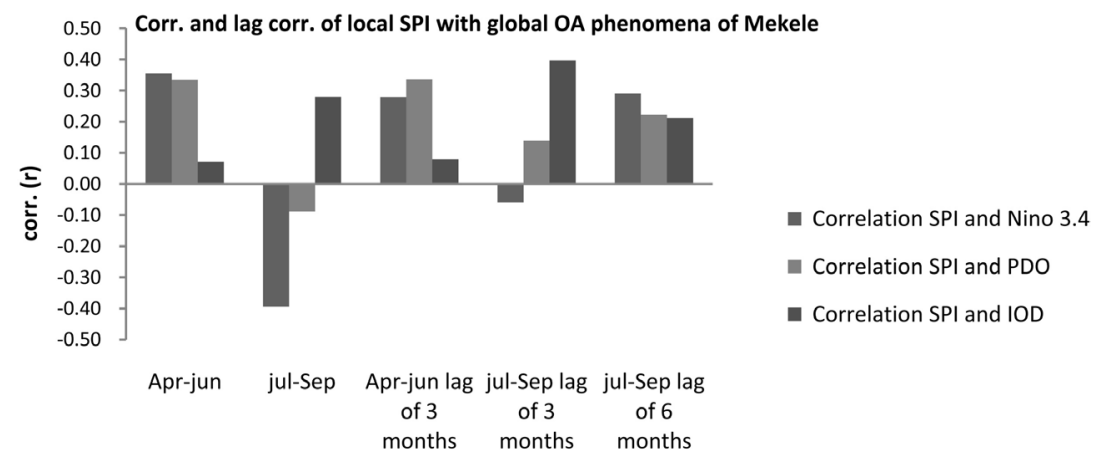

Figure 13. Correlation and lag correlation result of GOAP with local SPI. 
Table 3. Classification of deciles indices values and justification.

\begin{tabular}{ccc}
\hline Precipitations falls & DIs Ranges (\%) & Justification \\
\hline $10 \%-20 \%$ & 1 to 2 & Much below normal \\
$30 \%-40 \%$ & 3 to 4 & Below normal \\
$40 \%-60 \%$ & 5 to 6 & Near normal \\
$60 \%-80 \%$ & 7 to 8 & Above normal \\
$80 \%-100 \%$ & 9 to 10 & Much above normal \\
\hline
\end{tabular}

Source Gibbs \& Maher, 1967.

The lag correlations of (Figure 14) indicate Nino3.4, POD and IOD were positively correlated with both 3 and 6 lag months of the two rain seasons. These mean when the global Ocean Atmospheric phenomena were occurred 3 and 6 months before the drought were occur on the region. This is similar to years like 1989 and 2012 have less than -2 RDI value for July to Sep rain season which indicates extreme drought years.

The correlation result in (Figure 14) indicates that April to June rain fall positively correlated with Nino3.4, PDO and IOD and negatively correlated with SOI. It also indicates that July to Sep rain fall is negatively correlated with IOD and positively correlated with Nino3.4. The lag correlation of the station indicates that in both rain season the 3 month and 6 month lag RDI correlation is positive to Nino3.4, SOI, and IOD but negatively correlated with SIO and IOD. This indicates that the Global Ocean Atmospheric Phenomena have influence and stayed up to 3 - 6 months at local areas after the occurrences.

According to the deciles classification (Figure 15) the precipitation distribution of Mekele indicates that for years 1986, 2004 and 2016 rain was below normal and for 1982, 1985 and 2003 near normal but for 1983, 1987, 1988, 2000, 2006 and 2010 much above normal.

\subsection{Teleconnections of SPI and RDI with Global Indices for Adigudem}

Figure 16 \& Figure 17 shows that both Meteorological (SPI) and Agricultural drought (RDI) history of the station which indicates years 1930, 1939, 1951, 1972 and 1979 of July-Sep has SPI less than -1 this means that mild drought years. The same is true for RDI of year 1918, 1920, 1948, 1951, 1965 and 1970 of AprJune. Similarly like above stations the correlation between the indices of IOD peaks concedes with SPI and RDI for some years also for Nino3.4 and PDO and the events also associated with ENSO.

As compared to seasonal rainfall and the global indices under inter association of the local standardized precipitation Index (SPI) and reconnacence drought indices (RDI) with large scale global climate variables ENSO, PDO and IOD April to June and July to Sep rain seasons respectively which shows positive and or negative correlation for Adigudem station depending on the rain seasons. The annual correlation between the indices of IOD peaks concedes with SPI and RDI 


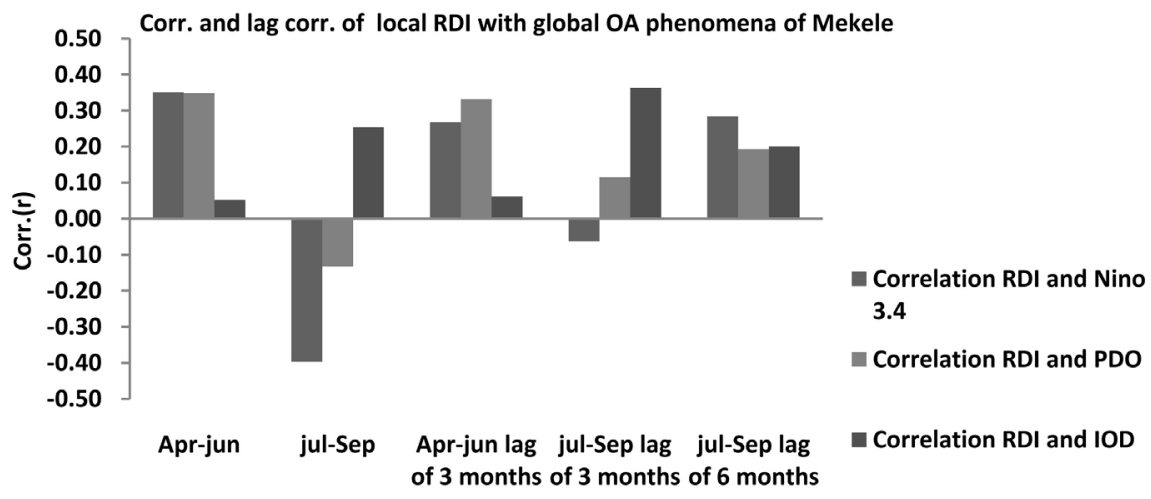

Figure 14. Correlation and lag correlation result of GOAP with local RDI.

\section{Deciles of Mekele station}

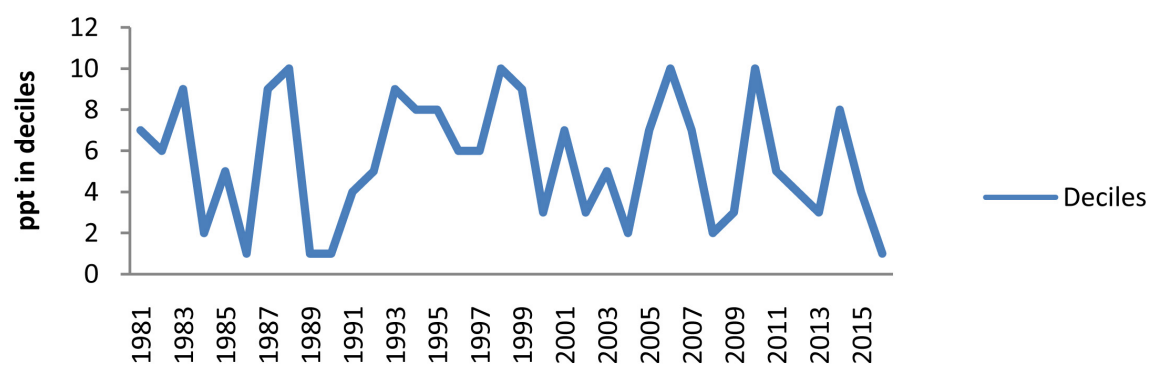

Figure 15. Precipitation distributions of Mekele stations.

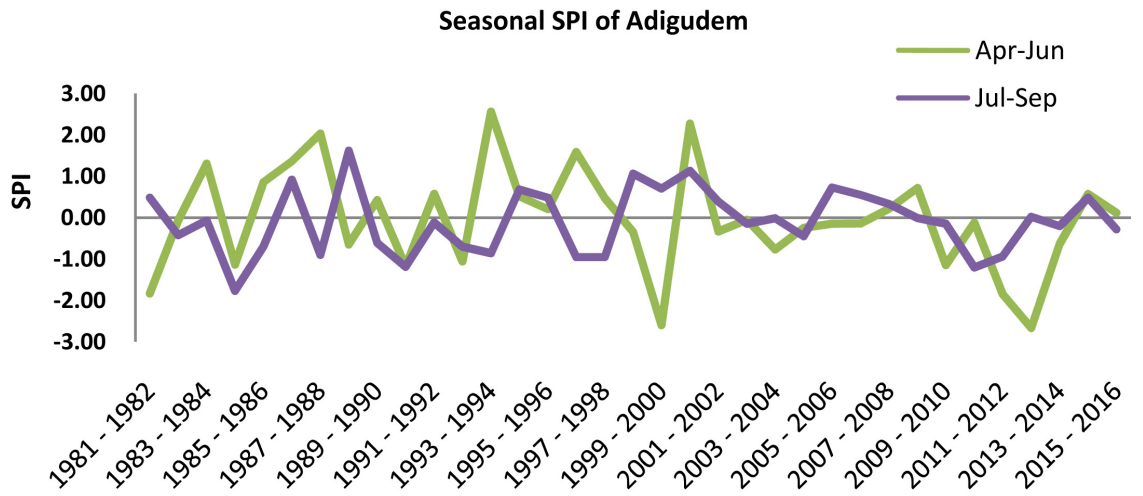

Figure 16. Teleconnections of annual SPI with global indices for Adigudem.

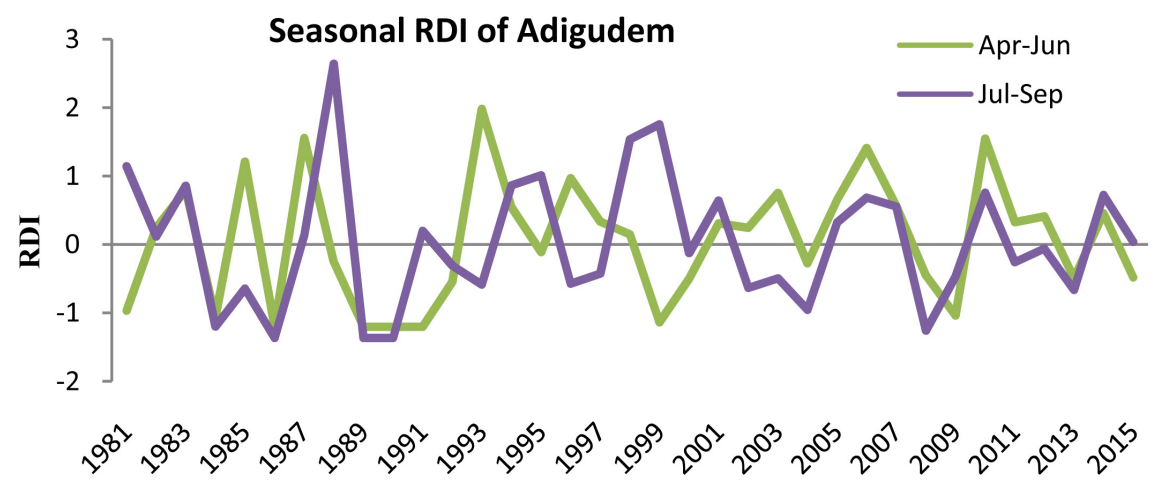

Figure 17. Teleconnections of annual RDI with global indices for Adigudem. 
some years and Nino3.4 and PDO peaks most of severe drought event years are associated with ENSO happening years.

Corr. and Lag Corr. of Local SPI with Global OA Phenomena of Adigudem The correlation result of (Figure 18) shows that Nino3.4 and PDO positively correlated with local SPI for April to June rain season and SOI and IOD are weakly correlated with SPI of July to Sept rain season The lag correlation in the figure shows that PDO is positively correlated with local SPI of 3 month lag of April to June rain season but negatively correlated for lag 3 months of July to Sept rain.

The correlation result of (Figure 19) shows that Nino3.4 and PDO positively correlated with local RDI of April to June rain. Similarly July to Sept rain correlated with SOI and IOD for RDI of station. The lag correlation of figure shows that PDO is positively correlated with local RDI of 3 months lag of April to June and 6 months lag July-Sept rain season but negatively correlated for lag 3 months of July to Sept rain.

The deciles (Figure 20) explained that the precipitation distributions of the station which is below normal for ppt values of $1 \%-2 \%$ and above normal for ppt ranges from $9 \%-10 \%$.

\subsection{Teleconnections of SPI and RDI with Global Indices for Adishushay}

Figure 21 \& Figure 22 indicates that the annual SPI years of some years like 1952 and 1966 of Apr-Jun and Jul-Sep lies on severe drought respectively in contrast 1935 and 1951 are ranged as non-drought categories.

Similarly the correlation analysis of (Figure 21) indicates that like other stations indices of IOD peaks concedes with SPI and RDI for some years also for Nino3.4 and PDO.

The correlation and the lag correlation result of the (Figure 21) indicates that the pacific decadal oscillation (PDO) positively influence or correlated with the local standardized precipitation index except Jul-sep rain season but Nino3.4 is negatively correlated with normal and lag of Jul-sep rain season. Figure 21 \& Figure 22 indicates that the annual SPI and RDI for 1951 July-Sep and 1966

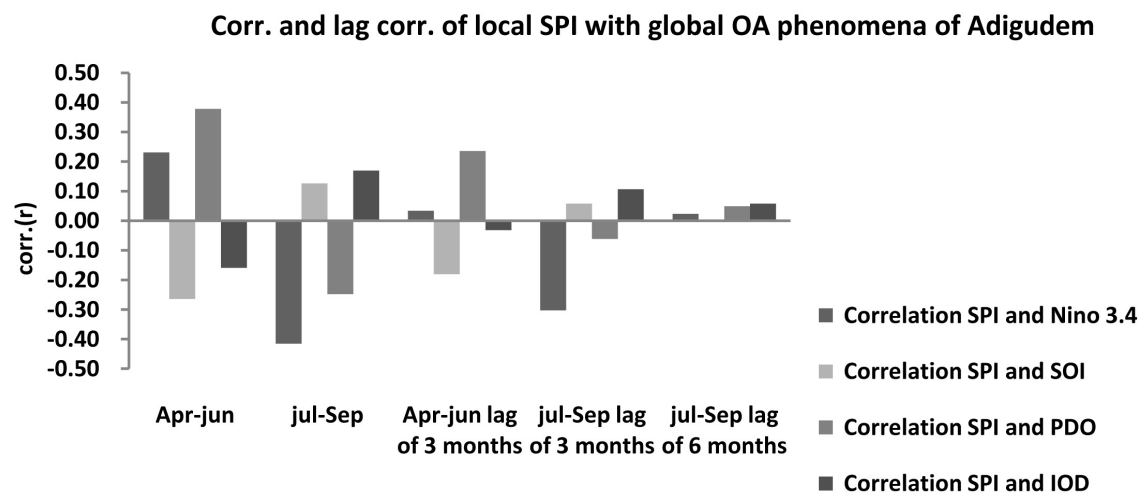

Figure 18. Correlation and lag correlation result of GOAP with local SPI of Adigudem. 


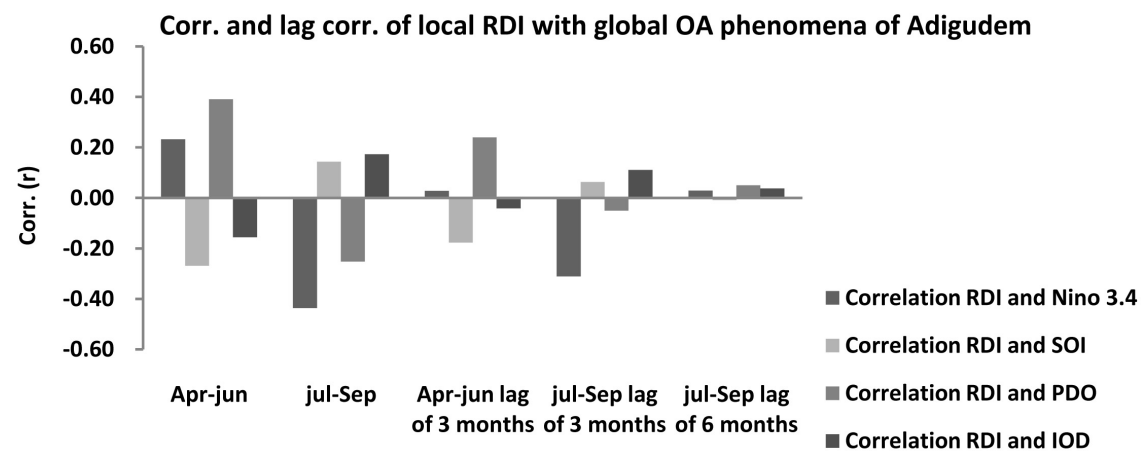

Figure 19. Correlation and lag correlation result of GOAP with seasonal RDI of Adigudem.

\section{Decile for Adigudem}

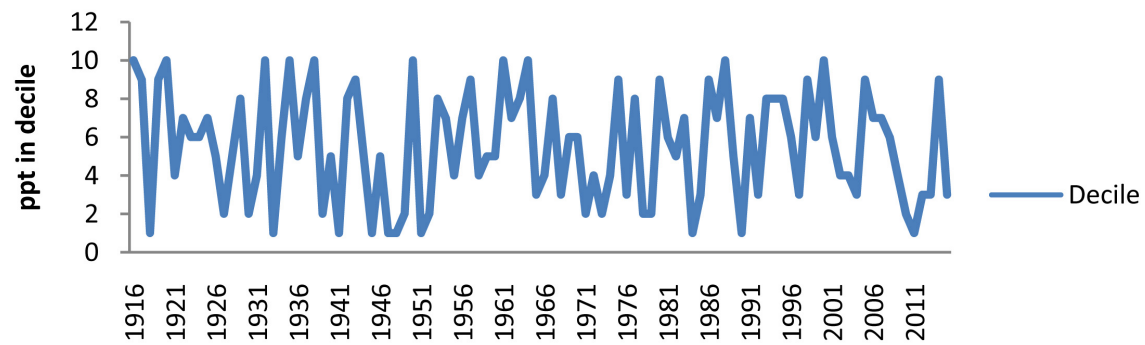

Figure 20. Precipitation distributions of Adigudem stations.

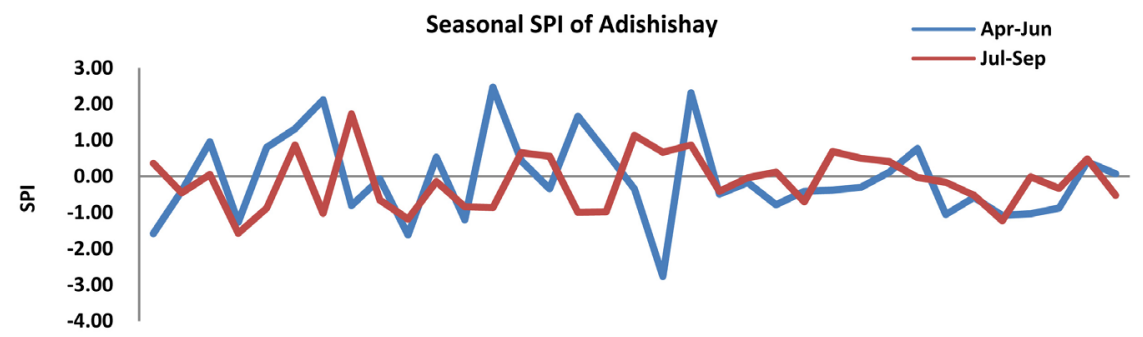

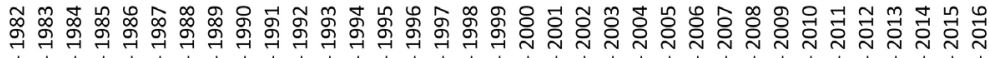

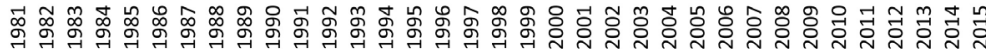

Figure 21. Teleconnections of annual SPI with global indices for Adishushay.

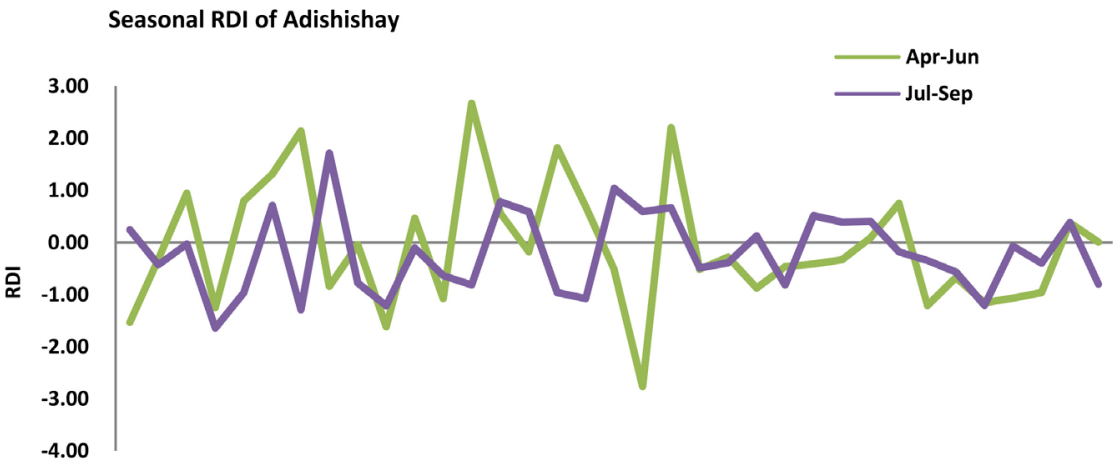

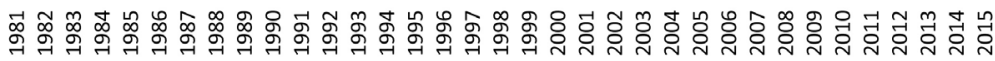

Figure 22. Teleconnections of annual RDI with global indices for Adishushay. 
April-Jun respectively less than-2 SPI and RDI values which indicates extreme drought for both SPI and RDI.

The comparison to seasonal rainfall and the global indices the station analysis under the inter association of the local SPI and (RDI) with ENSO, PDO and IOD has positive and or negative correlation for the station depending on its rain seasons. The annual correlation between the indices of ENSO peaks concedes with SPI and RDI for several drought years and PDO peaks some drought years.

\section{Correlation and Lag Correlation of the Local and Global Indices}

The correlation and the lag correlation result of SPI with global ocean atmospheric phenomena of Adishushay station is showed in Figure 23. The El Niño/ Southern Oscillation (ENSO) is well-known as a dominant mode of inter-annual climate variability that develops from air sea interactions in the tropical Pacific, but affects weather patterns globally. During an El Niño, air sea interactions promote the growth of positive SST and sea level anomalies in the central and eastern Pacific and corresponding negative and/or positive anomalies depends on in the stations of the study area.

\section{Conclusion and Recommendations}

The global indices Nino3.4, IOD and PDO coincided with local droughts SPI \& RDI for some years however Nino3.4 is the common factor for drought event and also PDO and IOD does. The strong correlations of global indices (Nino3.4, IOD and PDO) with local indices weaken the rain fall distribution for April to June rainy season. While SOI and IOD indices weaken July-Sep.

The positive correlation of indices weakened and/or dislocated the rain-producing components for main rainy season, while those systems enhanced in low rain season. This shows global indices alter rain fall distribution \& conveys Meteorological and Agricultural drought

The lag correlation also shows that PDO strongly correlated with Lag3 and lag6 months of April to June and July to Sept SPI of rain seasons respectively but weak for IOD.

The positive correlation and lag correlation of Nino3.4 with SPI indicates Nino3.4 is the dominant global influence for most stations of the region.

Corr. and lag corr. of local SPI with global OA phenomena of Adishishay

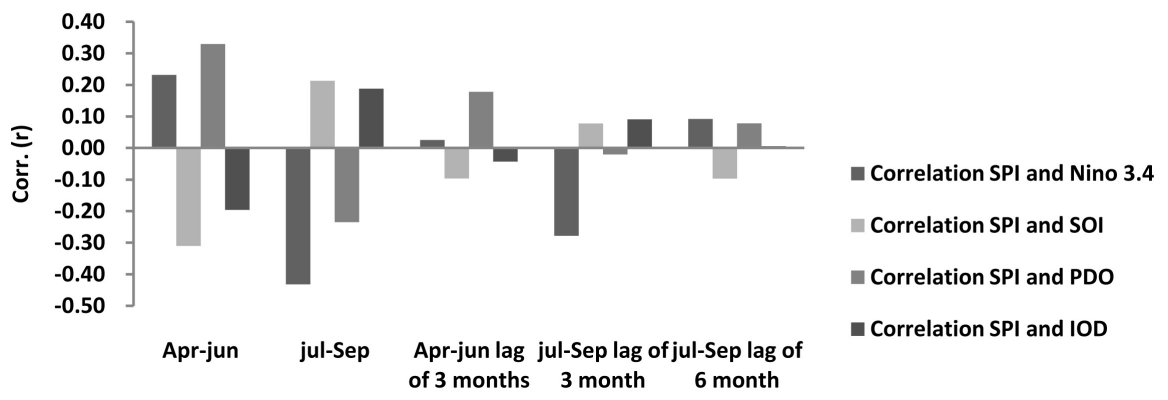

Figure 23. Correlation result of GOAP with local SPI of Adishishay. 
Most of non-drought years with normal and above normal rainfall (1970, 1971, 1973 1974, 197519881998 and 1999) negatively correlated with ENSO events while some of drought years coincide with ENSO years (1972, 1982, 1987, 1991, 1997, 2002 and 2004).

For most stations Southern Oscillation Index (SOI) is positively/Negatively correlated to the July-Sept/Apr-June rains respectively. Similarly, Sea surface Temperature (SST) of central and eastern Pacific (Nino3.4) is negatively correlated to July-Sept rains and positively correlated to Apr-June rain season.

During El-Nino years, the atmospheric circulations particularly in the tropics would be disturbed. Global indices Nino3.4, SOI, PDO and IOD shows both positive and negative influence depending on the weather station thus the study revealed that in addition to El Nino impacts; PDO, SOI and IOD are important factors for triggering Meteorological and Agricultural droughts in the region.

Understanding the teleconnection patterns related to either IOD or ENSO and their positive/negative interference during years of co-occurrence is very important from a societal viewpoint because people at large suffer from their regional influences rather than the coupled phenomena.

Not only Elnino3.4 but also other global ocean atmospheric phenomena Teleconnections (PDO, SOI and IOD) have significant role for Meteorological drought (SPI) and Agricultural drought (RDI) of the region.

Independent as well as combined impacts of global Ocean-Atmospheric coupled phenomenon with local indices (SPI and RDI) strengthening the extreme weather events of the region such climate signals also alarming peoples for alternate adaptation options. As a lag correlation results the influence of the global phenomena persistent over several months after its occurrence this may strengthening the drought events.

Finally, in fact there are also numerous mountains and valleys which could influence and make the weather of Ethiopia more complicated. It is believed that, the study will be continued with additional meteorological stations to map, interpolate and correlate the teleconnections of global indices with local SPI and RDI.

\section{Conflicts of Interest}

The author declares that there is no conflict of interest.

\section{References}

Bekele, F. (1997). Ethiopian Use of ENDO Information in Its Seasonal Forecast. https://www.semanticscholar.org/paper/Ethiopian-Use-of-ENSO-Information-in-Its-S easonal-Bekele/9a3a47b354f16f563a1170b74240c4ffc1143bbb

Beyene, A., Gibbon, D., \& Haile, M. (2005). Heterogeneity in Land Resources and Diversity in Farming Practices in Tigray, Ethiopia. Agricultural Systems, 88, 61-74. https://doi.org/10.1016/j.agsy.2005.06.004

Cf. Philander, S. G. H. (2004). Our Affair with El Niño. Princeton, NJ: Princeton Univ. Press. https://doi.org/10.1515/9780691187921 
Commonwealth of Australia (2016). The Indian Ocean Dipole. http://www.bom.gov.au/index.php

Dawit, A. (2010). Future Climate of Ethiopia from PRECIS Regional Climate Model EXperimental Design.

Gibbs, W. J., \& Maher, J. V. (1967). Rainfall Deciles as Drought Indicators. Bureau of Meteorology Bulletin No. 48, Melbourne: Bureau of Meteorology.

Gisila, T. et al. (2015). Ethiopian Panel on Climate Change, First Assessment Report, Working Group I Physical Science Basis, Published by Ethiopian Academy of Sciences.

Hassan, R. M. (2009). Implications of Climate Change for Agricultural Sector Performance in Africa: Policy Challenge and Research Agenda. Journal of African Economies, 19, ii77-ii105. https://doi.org/10.1093/jae/ejp026

IPCC (2000). Intergovernmental Panel on Climate Change (2000b): Climate Change 2000Impacts, Adaptations and Mitigation of Climate Change: Scientific-Technical Analyses. Contribution of Working Group II to the Second Assessment Report of the Intergovernmental Panel on Climate Change. Cambridge, New York: Cambridge University Press.

IPCC (2007). Climate Change 2007: Synthesis Report. Contribution of Working Groups I, II and III to the Fourth Assessment Report of the Intergovernmental Panel on Climate Change. Geneva: IPCC.

JAMSTEC (2008). Indian Ocean Dipole. http://www.jamstec.go.jp/frcgc/research/d1/iod/e/iod/about_iod.html

Komuscu, A. U. (1999). Using the SPI to Analyse Spatial and Temporal Patterns of Drought in Turkey. Drought Network News, 11, 7-13.

Korecha, D. et al. (2013). Recent Drought and Precipitation Tendencies in Ethiopia.

Mantua (2000). The Pacific Decadal Oscillation (PDO).

http://www.jisao.washington.edu/pdo

McKee, T. B., Doesken, N. J., \& Kleist, J. (1993). The Relationship of Drought Frequency and Duration to Time Scales. In Eighth Conference on Applied Climatology (pp. 5-6). Boston, MA: American Meteorological Society.

Molla, M. (2016a). Climate Variability, Its Impact on Maize Production and Adaptation Options: Case Study of Halaba Special Woreda, Southern Ethiopia.

Molla, M. (2016b). Prediction of Future Climate and Its Impact on Crop Production Case Study of Hadiya Zone, Southern Ethiopia.

National Meteorological Service Agency of Ethiopia (NAPA) (2007). Climate Change National Adaptation Programme of Action (NAPA) of Ethiopia. Addis Ababa.

NMA (2007). Climatic and Agro-Climatic Resources of Ethiopia. Meteorological Research Report Series, Addis Ababa.

NOAA (2016). Pacific Decadal Oscillation (PDO). http://www.ncdc.noaa.gov

NOAA Earth System Research Laboratory, Physical Science Division, El Niño Southern Oscillation (ENSO). http://www.esrl.noaa.gov/psd/enso/index.html

Obasi, G. O. P. (1994). WMO's Role in the International Decade for Natural Disaster Reduction. Bulletin of the American Meteorological Society, 75, 1655-1661.

Seleshi, Y., \& Camberlin, P. (2006). Recent Changes in Dry Spell and Extreme Rainfall Events in Ethiopia. Theoretical and Applied Climatology, 83, 181-191. https://doi.org/10.1007/s00704-005-0134-3

Smakhtin \& Hughes (2004). Assessing the Historical Frequency of Drought Events on Grazing Properties in the Rangelands. Agricultural Systems, 57, 271-299. 
https://doi.org/10.1016/S0308-521X(98)00019-5

Tadesse, T. et al. (2009). The Impacts of Weather Extremes on Agricultural Production Methods: Does Drought Increase Adoption of Conservation Practice? Faculty Publications: Agricultural Economics. Paper 83, 17.

Tigkas (2015). Centre for the Assessment of Natural Hazards \& Proactive Planning \& Lab of Reclamation Works and Water Resources Management.

Wilhite, D. A. (1992). Drought. In Encyclopedia of Earth System Science (Vol. 2, pp. 81-92). San Diego, CA: Academic Press.

Wilhite, D. et al. (2000). Early Warning Systems for Drought Preparedness and Drought Management. In Proceedings of an Expert Group Meeting (pp. 148-151). Geneva: World Meteorological Organization.

\section{Lists of Abbreviations}

SPI: Standardized Precipitation Index

RDI: Reconnaissance Drought Index

ENSO: El-Nino Southern Oscillation

Nino3.4: Oceanic Nino

IOD: Indian Ocean Dipole

PDO: Pacific Decadal Oscillation

NCEP: National Center for Environmental Prediction

NMA: National Meteorological Agency

KNMI: Koninklijk Nederland Meteorological Institute

ITCZ: Inter Tropical Convergence Zone

TEJ: Tropical Easterly Jet

EALLJ: East African Low Level Jet

SWJ: Westerly Jet

SSTA: Sea Surface Temperature Anomalies

NAO: North Atlantic Oscillation

PET: Potential Evapo-Transpiration

SDI: Stream Flow Drought Indices

GOAP: Global Ocean Atmospheric Phenomena 